\title{
In Situ Hybridisation Study of Neuronal Neuropeptides Expression in Models of Mandibular Denervation with or without Inflammation: Injury Dependant Neuropeptide Plasticity
}

Seham A Abd El-Aleem ${ }^{1^{*}}$ and Begonia M Morales-Aza ${ }^{2}$

${ }^{1}$ Department of Histology, Minia Faculty of Medicine, Egypt

${ }^{2}$ Department of Physiology, School of Medical Sciences, University of Bristol, Bristol, UK

*Corresponding author: Abd El-Aleem SA, Department of Histology, Minia Faculty of Medicine, Egypt, Tel: +201002997270; E-mail: Seham.abdelaleem@minia.edu.eg Received date: June 04, 2018; Accepted date: June 25, 2018; Published date: June 29, 2018

Copyright: (C) 2018 Abd El-Aleem SA, et al. This is an open-access article distributed under the terms of the Creative Commons Attribution License, which permits unrestricted use, distribution, and reproduction in any medium, provided the original author and source are credited.

\begin{abstract}
Neuronal expression of neuropeptides is altered following peripheral tissue injury associated with inflammation or nerve injury. This results in neuropathic pain with or without neurogenic inflammation which is a major health problem regularly seen in trigeminal neuralgia. Activation of the trigeminal system results in the release of vasoactive neuropeptides substance $P$ and Calcitonin Gene-related Peptide (CGRP) which contribute to nociception, pain and neurogenic inflammation in injured tissues.
\end{abstract}

Aim: To study the alterations in the neuronal neuropeptides expressions in models of tissue injury associated with either nerve injury or with inflammation and to determine if denervation would alter the neuronal response to inflammation.

Material and methods: Experiments were performed on rat mandibles to produce three models. Firstly, denervation model by sectioning one of the mandibular nerve branches (inferior alveolar nerve). Secondarily, inflammation model by intra-gingival injection of lipopolysaccharide (LPS). Thirdly, combined denervation and inflammation model by sectioning the nerve with subsequent LPS injection. The animals were sacrificed seven days postoperative. Trigeminal ganglia on the operated sides were processed for in situ hybridisation for neuropeptides; substance P and CGRP mRNAs. Images were analysed for morphological and morphometric analysis using Image $\mathrm{J}$ software.

Results: substance P and CGRP mRNAs were expressed in small and medium-size primary afferent neurons in the mandibular division of the trigeminal ganglia. Both the denervation and the inflammation models showed alteration in neuropeptides expression in the sensory primary afferent neurons innervating the affected mandibular tissues. While, denervation resulted in a significant (substance $P=P<0.04, C G R P=P<0.01$ ) downregulation contrarily, inflammation resulted in a significant $(P<0.001)$ upregulation of neuropeptides' mRNAs. Interestingly, denervation prior to induction of inflammation resulted in insignificant changes in neuropeptides levels. There was a strong correlation (Pearson Correlation $=0.8$ ) between substance P and CGRP expression.

Conclusion: We show that tissue damage associated with nerve injury or inflammation results in alteration of neuropeptides levels in the innervating primary afferent neurons. Tissue destruction associated with chronic inflammatory condition such as arthritis and periodontitis are believed to be due to the production of neuromodulators causing neurogenic inflammation. Here we show that denervation abolishes the neuronal response to inflammation. Therefore, tissues denervation could relieve neurogenic inflammation associated with chronic disorders through regulation of neuronal neuropeptide production. Moreover, the current model that combined denervation and inflammation provides a useful animal model to study the contribution of nerve-related mediators in the pathophysiology of tissue injury.

Keywords: Neuropeptides; Neurogenic inflammation; Denervation; Inflammation; Periodontitis

\section{Introduction}

Nervous system plays an important role in the regulation of nociception and pain associated with peripheral tissue injury $[1,2]$. Nerves secrete neuropeptides which are neuromodulators involved in signal transmission including substance $P$ and CGRP [3]. Neuropeptides are distributed both in the peripheral and in the central nervous system [4-7] and are also expressed in the peripheral tissues [8-10]. Neuropeptides are synthesized in the ganglion sensory cells and transmitted to the peripheral tissues $[1,3]$. Therefore, the peripheral expression of neuropeptides is partially attributed to neurotransmission from the neurons.

Peripheral stimuli from the orofacial region are transmitted mainly by the trigeminal nerve with its primary afferent neurons located in the trigeminal ganglion [11,12]. Mandibular nerve a branch of the trigeminal nerve provides somatosensory innervation to the mandibular region and its neurons are in the mandibular division of 
Citation: Abd El-Aleem SA, Morales-Aza BM (2018) In Situ Hybridisation Study of Neuronal Neuropeptides Expression in Models of Mandibular Denervation with or without Inflammation: Injury Dependant Neuropeptide Plasticity. J Cytol Histol 9: 509. doi: 10.4172/2157-7099.1000509

Page 2 of 8

the trigeminal ganglia [13]. Inferior alveolar nerve a branch of the mandibular nerve innervating mandibular structures gingiva, bone and teeth (periodontium) $[13,14]$.

Sectioning the inferior alveolar nerve has been used as a model for studying the effect of denervation on neuropeptides expression centrally in the neurons and locally on the mandibular tissues in health and disease [15-17]. Inflammation of the mandibular structures such as gingiva, gum and bone is referred to as periodontal disease $[18,19]$. LPS injection into the animal mandible has been used as a model of inflammation for studying the alteration in neuropeptides locally and centrally.

Substance P and CGRP were expressed in the sensory nerve terminals in the gingivae and the periodontium of different species [20-24]. In the trigeminal ganglia, neurons co-express both substance $\mathrm{P}$ and CGRP, where all substance $\mathrm{P}$ containing trigeminal ganglia cells were expressing CGRP [4-8]. Moreover, there is a correlation between substance $\mathrm{P}$ and CGRP and the interaction between them could modulate pain transmission [25-29]. During inflammation, the expression of substance $\mathrm{P}$ and CGRP changes in the trigeminal ganglia neurons [30,31] and in the local nerve terminals innervating the inflamed tissues [21-24]. Therefore, neuropeptides play important parts in homeostasis and repair of the innervated tissues and were associated with trigeminal and trigeminovascular disorders [32-36]. We hypothesize that the alteration in neuronal neuropeptide in response inflammation could be modulated by nerve sectioning and this could be the mechanism of relieving pain by tissue desensitization.

\section{Material and Methods}

All animal procedures conformed to UK legislation and local ethical review. Adult male Wistar rats, (225-250 g) were ordered and housed few days prior to the experiment.

\section{Denervation by sectioning the inferior alveolar nerve}

Animals were anesthetized by Hypnorm $0.3 \mathrm{mg} / \mathrm{kg}$ (fentanyl citrate $0.1 \mathrm{mg} / \mathrm{kg}$ and fluanisone $3 \mathrm{mg} / \mathrm{kg}$ ) administered intramuscularly, followed by Diazepam $2.5 \mathrm{mg} / \mathrm{kg}$ intraperitoneally. The face of the animal was shaved and an incision was made extending from the angle of the mouth to the ear with care not to injure the parotid gland or the facial nerve.

The mandible was exposed by dissecting through the skin, then through the masseter muscle in between the two branches of the facial nerve running across the muscle. A hole was made in the mandibular canal close to the incisor root to get the nerve out of the canal. The nerve was held up and cut (denervated group), then the muscle and the skin were sutured to close the wound. The same procedure was done for the sham group but without cutting the nerve (sham control group).

\section{LPS-Induction of mandibular inflammation (Periodontitis)}

To induce mandibular inflammation a single dose of $1 \mu \mathrm{l}$ lipopolysaccharide (LPS: $10 \mathrm{mg} / \mathrm{ml}$ in saline) (inflammation group) or vehicle (vehicle control group) was injected intra-gingival between the first and second mandibular molars [17], under anaesthesia as above. Animals were given one low dose subcutaneous injection of nonsteroidal anti-inflammatory (Rimadyl $100 \mu \mathrm{l}$ ) to minimize the acute pyrexia resulting from LPS injection. Animals were kept warm until full recovery and were checked for any immediate adverse effects of the LPS injection prior to housing under standard conditions (12-hour light: dark cycle, and fed normal rat pellets).

\section{Animal grouping and tissue harvesting}

Animals were grouped as follow; nerve sectioning (denervation group, 3 rats), LPS injection (inflammation group, 4 rats). Nerve sectioning and LPS injection on the same side (combined denervation with inflammation group 6 rats). Control groups included; (sham control 3 rats), (vehicle control 4 rats) and combined sham with vehicle injection on the same side (sham vehicle control, 3 rats). Seven days postoperative, the animals were killed by decapitation under light halothane anaesthesia. The trigeminal ganglia on the operated sides were removed, embedded in OCT and stored at $-80^{\circ} \mathrm{C}$ for subsequent cryosectioning.

\section{In situ hybridization}

In situ hybridization was performed, as previously described [25]. Briefly, 35S-labelled cRNA probes were synthesised by in vitro transcription from cDNAs encoding preprotachykinin (substance $\mathrm{P}$ ) and a-CGRP (CGRP) using SP6 RNA polymerase (Promega, Southampton, UK), 35S-labelled UTP $(800 \mathrm{Ci} / \mathrm{mmol}$, Amersham Int., Amersham, UK) and unlabelled UTP (Boehringer, Mannheim, Germany), to a specific activity of 3-5 $108 \mathrm{Ci} / \mathrm{mmol}$. $10 \mu \mathrm{m}$ cryostat sections of trigeminal ganglia were mounted on gelatin/poly-L-lysine coated slides, fixed in $4 \%$ paraformaldehyde in $0.1 \mathrm{M}$ phosphate buffer for 10 minutes and rinsed three times in 2 SSC (standard saline citrate).

Sections were hybridized with approximately 106 counts per $\mathrm{ml}$ in hybridization buffer in sealed humid containers at $55^{\circ} \mathrm{C}$. After hybridization sections were treated with RNaseA to remove the nonspecific binding then washed to a maximum stringency of 0.1 SSC at $55^{\circ} \mathrm{C}$ for one hour. Sections were dehydrated in graded ethanols in 0.3 $\mathrm{M}$ sodium acetate, air dried and exposed to auto radiographic film. Following film exposure, slides were dipped in $\mathrm{K} 5$ nuclear emulsion (Ilford, UK) and exposed at $4^{\circ} \mathrm{C}$ for up to ten days. Slides were developed, counterstained with hematoxylin and eosin and coverslipped for microscopic examination and image analysis. Negative control sections in which the probe was omitted were processed with each in situ run. Sections were examined on a computerized image analysis system (colour still or video camera attached to a Nikon E600 Eclipse attached to Macintosh G4 computer). The positive staining signals (mRNA) were identified by the presence of silver grains (black dots in the bright field) overlaying the cell body of the neurons. Figure $1 \mathrm{~A}$ and $1 \mathrm{~B}$ show the staining pattern. 
Citation: Abd El-Aleem SA, Morales-Aza BM (2018) In Situ Hybridisation Study of Neuronal Neuropeptides Expression in Models of Mandibular Denervation with or without Inflammation: Injury Dependant Neuropeptide Plasticity. J Cytol Histol 9: 509. doi: 10.4172/2157-7099.1000509

Page 3 of 8
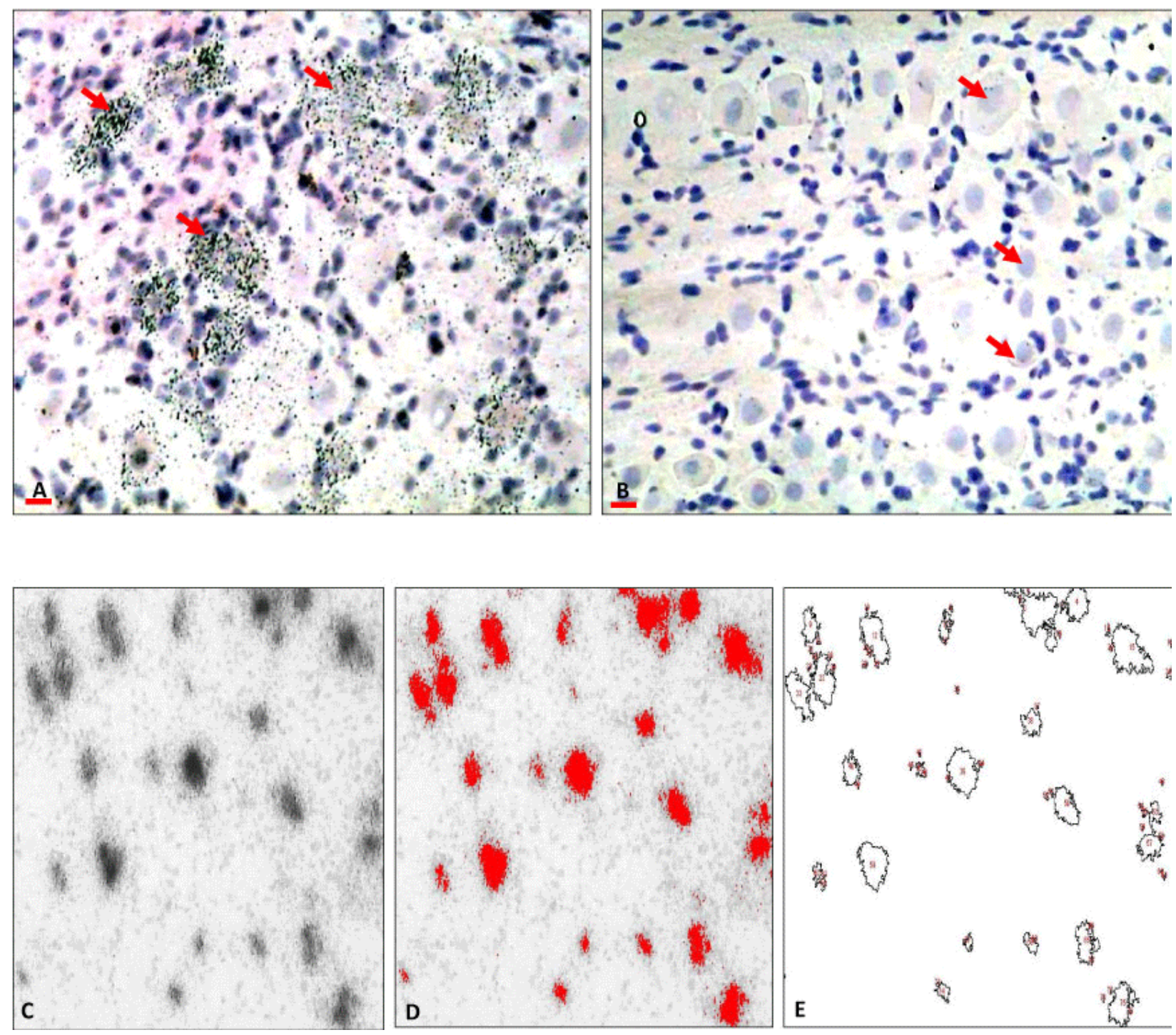

Figure 1: A representative photomicrographs of the trigeminal ganglia showing signal of the in situ hybridization staining and the negative control to validate the technique: A) Silver grains (black dots) are seen overlaying the neurons expressing mRNAs. B) Negative sections in which the probe was omitted showing a complete absence of the silver grains. Scale bars: A, B=50 $\mu$. C-E) A representative photomicrograph demonstrating image J analysis of in situ hybridisation signals. A) Original image. Silver grains are seen as black dots overlaying the neurons which contain the mRNA. B) Converted image, in situ hybridisation signals, were converted into a distinct colour (red) that the software can score. C) Showing the scored neurons (analysed neurons=outlined structures) with exclusion of the background. The analysis provides information about the number of neurons analysed and the levels of the mRNAs per neuron.

\section{Image analysis}

Autoradiography and computerized image analysis were used to visualize and quantify the hybridization signal. Image $J$ software developed at the U.S. National Institutes of Health was used for the quantification. The levels of mRNA per neuron were determined by counting silver grains overlying cell bodies of neurons $[25,26]$ in the mandibular division of the trigeminal ganglia. The analysis was done for only small size neurons (less than $30 \mu \mathrm{m}$ diameter) filtered by the software in each of nine individual sections from each animal. The silver grain numbers are represented by the number of the pixels covered by the silver grains for each neuron. Figure 1C-E demonstrates the steps for measuring mRNA levels.

\section{Data analysis}

Statistical analyses were performed using IBM SPSS statistical package. Results were expressed as the mean \pm SEM. Expression data were compared using one-way ANOVA comparing the expression levels in each experimental group to those in the corresponding control groups, with $\mathrm{P}<0.05$ being considered as statistically significant. 
Citation: Abd El-Aleem SA, Morales-Aza BM (2018) In Situ Hybridisation Study of Neuronal Neuropeptides Expression in Models of Mandibular Denervation with or without Inflammation: Injury Dependant Neuropeptide Plasticity. J Cytol Histol 9: 509. doi: 10.4172/2157-7099.1000509

Page 4 of 8

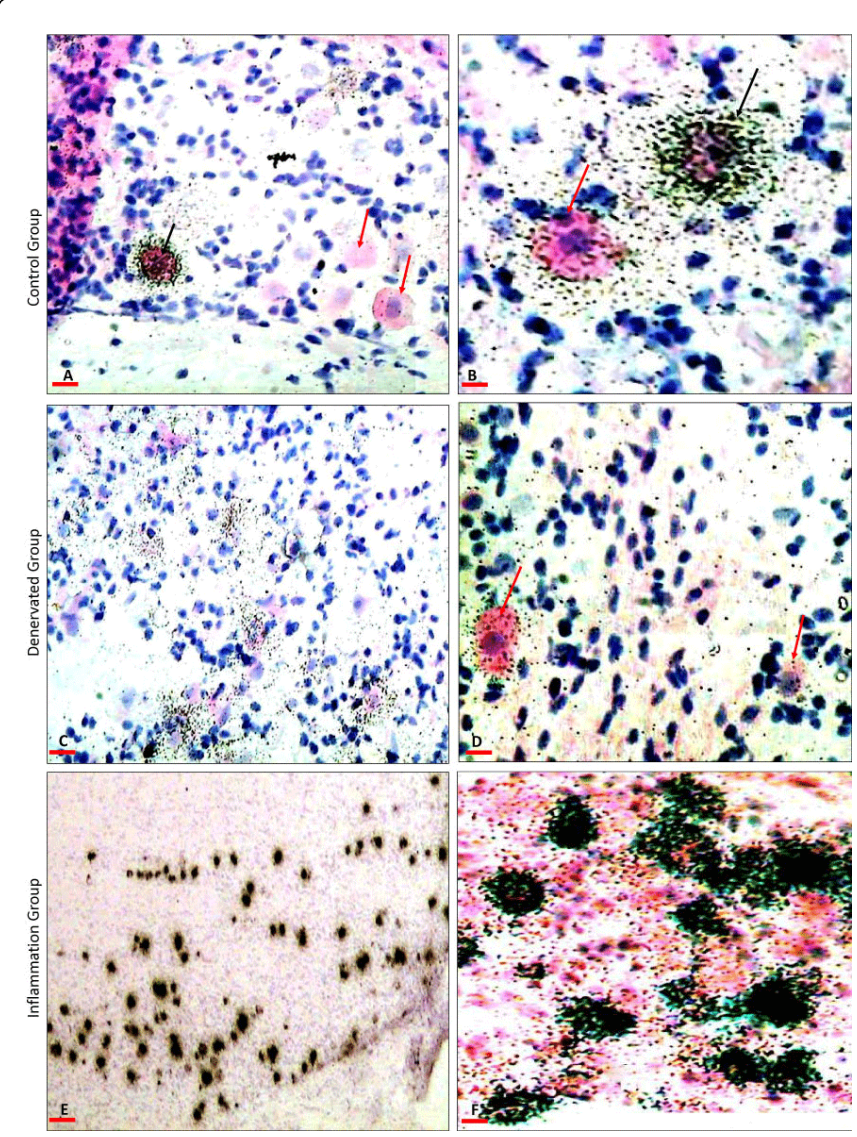

Figure 2: A representative photographs showing substance P mRNA Expression in the mandibular division of the trigeminal ganglia: A) Control trigeminal ganglia showing substance P mRNA expression in neurons only. The positive neuron shows silver grain overlaying the cells (black arrows). B) A higher magnification showing, a variable degree of expression ranging from weak (red arrows) to mild (black arrow). C) Trigeminal ganglia from animals with denervated mandible showing a marked reduction in substance $\mathrm{P}$ mRNA in the neurons. Most of the neurons show weak expression. D) Higher magnification showing discrete silver grain overlaying the positive neurons, indicating the low expression (red arrows). E) Trigeminal ganglia from animal with inflamed mandible showing apparent increase in substance $\mathrm{P}$ mRNA expression, there is increase in the number of the positive neurons and increase in the expression per neuron. F) A higher magnification showing the coalescence of the silver grains masking the nuclei indicating the marked increase in substance $\mathrm{P}$ expression per neuron. Scale bars: $\mathrm{A}, \mathrm{D}, \mathrm{F}=50 \mu ; \mathrm{B}=20 \mu, \mathrm{C}=100 \mu, \mathrm{E}=400 \mu$.

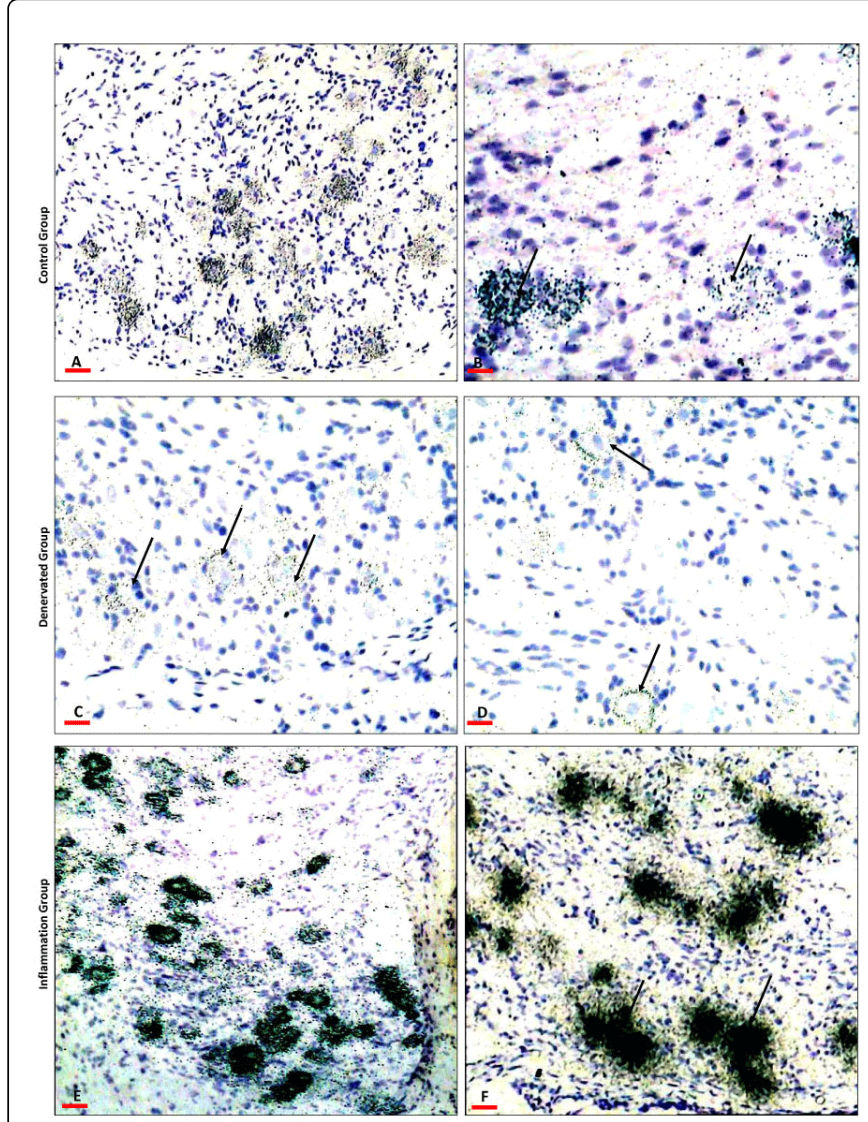

Figure 3: A representative photographs showing CGRP mRNA in the mandibular division of the trigeminal ganglia: A, B) Control trigeminal ganglia, showing CGRP expression in neurons only (arrows). There is wider distribution than substance $\mathrm{P}$ as seen in the increase in number of positive neurons. C, D) Trigeminal ganglia from animals with Denervated mandible showing marked reduction in the substance P mRNA in the neurons (arrows). D) Higher magnification showing discrete silver grain distribution overlaying the positive neurons indicating the low expression, the expression was almost limited to the sub membranal cytoplasmic compartment with depletion from the perinuclear cytoplasmic compartment (arrows). E) Trigeminal ganglia from animal with inflamed mandible showing marked increase in CGRP mRNA expression, there is an increase in the number of the positive neurons. F) Higher magnification showing the coalescence of the silver grains masking the nuclei (arrows) indicating the marked increase in CGRP expression per neuron. Scale bars: $A=200 \mu, B=50$ $\mu, C, D=100 \mu, E=300 \mu, \mathrm{F}=200 \mu$. 
Citation: Abd El-Aleem SA, Morales-Aza BM (2018) In Situ Hybridisation Study of Neuronal Neuropeptides Expression in Models of Mandibular Denervation with or without Inflammation: Injury Dependant Neuropeptide Plasticity. J Cytol Histol 9: 509. doi: 10.4172/2157-7099.1000509

Page 5 of 8

\section{Results}

\section{Microscopic examination of neuropeptides expression in control and experimental groups}

Neuropeptides; substance P and CGRP mRNAs were expressed in the mandibular division of the trigeminal ganglia from both the control and the experimental groups.

There was variability in the intensity of silver grains indicating variability in the level of expression of neuropeptides in different groups (Figures 2,3). The expression was exclusively cytoplasmic in the ganglion neurons. Substance P was expressed in small and mediumsized neurons and CGRP was expressed in small, medium and large size neurons.

The quantitation of substance P and CGRP mRNA (Table 1) was performed by a software image J programme which measured the size of neurons and the levels of mRNA per neuron by counting the number of silver grain overlaying the neurons. mRNA levels were measured in the small size neurons (less than $30 \mu \mathrm{m}$ diameter), which are known to be the sensory neurons associated with nociception.
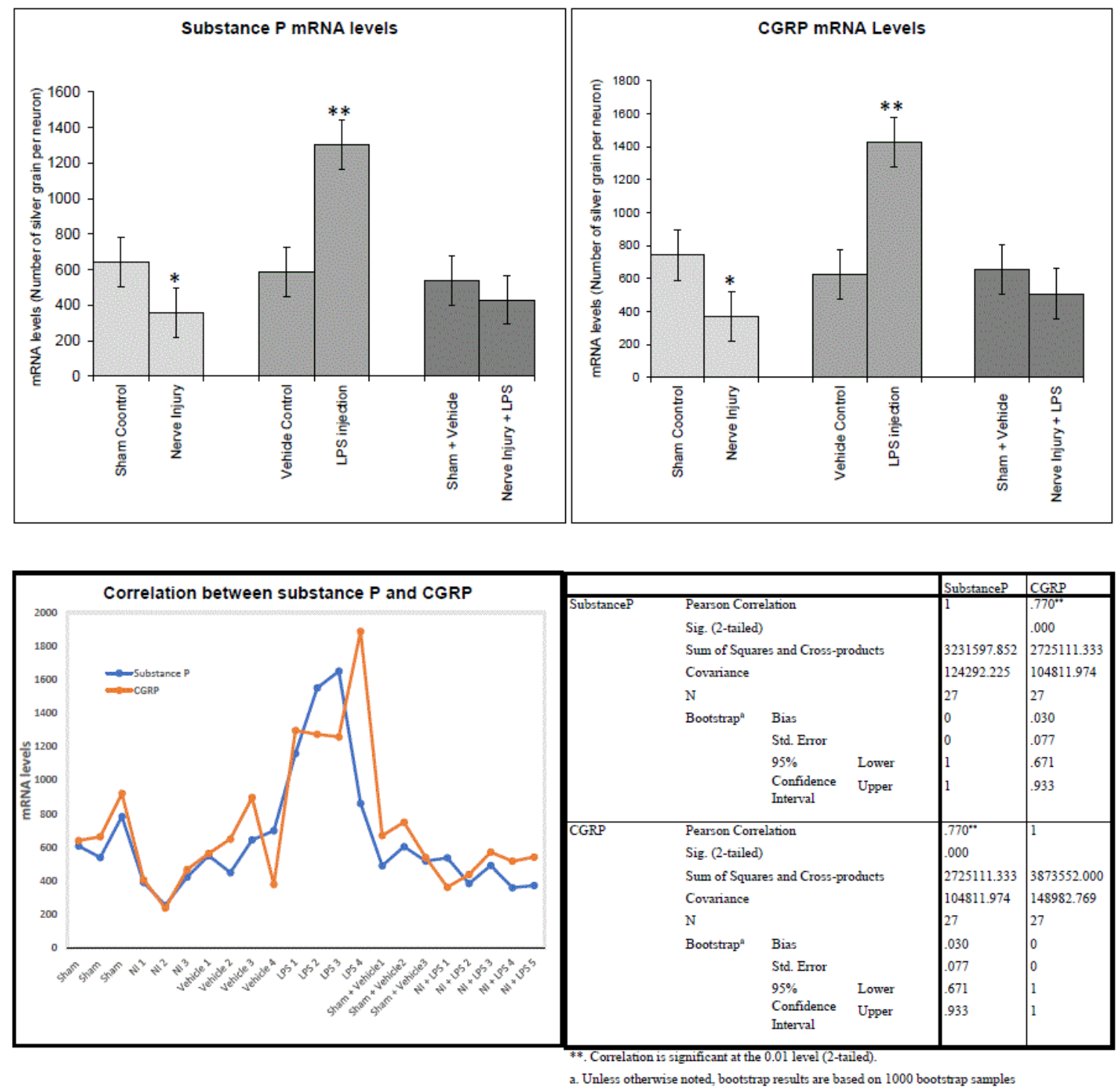

Figure 4: A,B Graphs showing mRNA levels of substance P and CGRP mRNAs in the three groups: Denervated group shows a significant (substance $\mathrm{P} . \mathrm{P}<0.04$; CGRP, $\mathrm{P}<0.01$ ) downregulation by comparison to the control sham group. Contrarily, inflammation group shows a significant $(\mathrm{P}<0.001)$ upregulation by comparison to the vehicle control group. Interestingly, denervation of the mandible prior to induction of inflammation abolished the stimulatory effect of LPS on neuropeptides mRNAs. C) A graph showing a strong correlation between substance P and CGRP mRNAs expression (Pearson Correlation=0.8). D) A table summarizing the correlation data between substance P and CGRP. 
Citation: Abd El-Aleem SA, Morales-Aza BM (2018) In Situ Hybridisation Study of Neuronal Neuropeptides Expression in Models of Mandibular Denervation with or without Inflammation: Injury Dependant Neuropeptide Plasticity. J Cytol Histol 9: 509. doi: 10.4172/2157-7099.1000509

Page 6 of 8

\section{Effect of mandibular denervation on the neuropeptides levels in the trigeminal ganglion}

Sectioning of the inferior alveolar nerve resulted in downregulation in the expression of the neuropeptides; substance P and CGRP in the primary afferent neurons in the mandibular division of the trigeminal ganglia on the operated side. Substance P showed a significant $(<0.04)$ downregulation (Figures $2 \mathrm{C}, 2 \mathrm{D}, 4 \mathrm{~A}$ ) by comparison to the control (Figures 2A, 2B, 4A). Similarly, CGRP showed a significant $(\mathrm{P}<0.01)$ downregulation (Figures 3C, 3D, 4B) by comparison to the control (Figures 3A, 3B, 4B). Table 1 summarizes the levels of substance $\mathrm{P}$ and CGRP in the control and in the denervated groups.

\section{Effect of LPS induced mandibular inflammation on the neuropeptides levels in the trigeminal ganglia}

LPS induced inflammation in the rat mandibular tissues resulted in upregulation in the expression of the neuropeptides; substance $\mathrm{P}$ and CGRP in the primary afferent neurons innervating the inflamed mandible (Figures 2-4). Substance $\mathrm{P}$ showed a significant $(\mathrm{P}<0.001)$ upregulation (Figures 2E, 2F, 4A) by comparison to the control (Figures 2A, 2B, 4A). Similarly, CGRP showed a significant $(\mathrm{P}<0.001)$ upregulation (Figures $3 \mathrm{E}, 3 \mathrm{~F}, 4 \mathrm{~B}$ ) by comparison to the control (Figures $3 \mathrm{~A}, 3 \mathrm{~B}, 4 \mathrm{~B})$. Table 1 summarizes the levels of substance $\mathrm{P}$ and CGRP in the control and in the LPS injected groups.

\section{Effect of mandibular denervation and LPS induced inflammation on neuropeptides levels in the trigeminal ganglia}

LPS injection in the denervated mandible showed no significant changes in substance P and CGRP expression in the primary afferent neurons in the mandibular division of trigeminal ganglia on the operated side by comparison to the sham-vehicle control group (Figure $4 \mathrm{~A}, 4 \mathrm{~B})$. Therefore, nerve sectioning abolished the stimulatory effect of LPS on neuronal neuropeptides production. Table 1 summarizes the levels of substance P and CGRP in the control and in the denervated/ inflamed groups. Correlation analysis including all the experimenta groups showed a strong correlation (Pearson Correlation=0.8) (Figure 4C) between substance $P$ and CGRP. This indicates that both neuropeptides show a simultaneous change.

\begin{tabular}{|l|l|l|}
\hline Groups & Substance P & CGRP \\
\hline Sham Control & $644 \pm 73$ & $741.9 \pm 90$ \\
\hline Denervated & $356 \pm 40^{*}$ & $371.3 \pm 53^{*}$ \\
\hline Vehicle Control & $586.6 \pm 49$ & $623 \pm 133$ \\
\hline Inflammation & $1305.3 \pm 163^{* *}$ & $1429.5 \pm 137^{* *}$ \\
\hline Sham+Vehicle & $538.3 \pm 27$ & $653.7 \pm 47$ \\
\hline Denervation and inflammation & $429.8 \pm 36$ & $508.7 \pm 38$ \\
\hline *P value<0.05, ${ }^{* *} \mathrm{P}<0.001$ & & \\
\hline
\end{tabular}

Table 1: Changes in the levels of substance P and CGRP mRNAs in the primary afferent neurons of the mandibular divisions of the trigeminal ganglia on the operated side. Readings represent the number of silver grains (mRNA) per neuron expressed as mean \pm SEM.

\section{Discussion}

Attention has been given to the contribution of the nervous system to inflammatory and healing responses after tissue injury [37]. Several evidences show that neuropeptides such as substance P and CGRP, released from nerve endings, are involved in the host response [38-40]. Different animal models were used to explain the association between the central changes in the innervating neurons and the changes in the local tissues where the nerve ends. These models included either denervation models or inflammation models [40-42]. Here, we have used a denervation model and an inflammation model and we have endorsed our study by using a combined denervation-inflammation model. The three models were used in the same experimental setting, on the same species and under same environmental and experimental conditions to avoid the discrepancies in the results which could result from difference in species, environmental conditions... etc.

Here, we showed that peripheral tissue injury is associated with a concomitant alteration in the neuropeptides centrally in the innervating neurons. While denervation of rat mandible by sectioning one of its branches was associated with downregulation of substance $\mathrm{P}$ and CGRP mRNAs in the trigeminal ganglion neurons innervating the affected area. Contrary, induction of mandibular inflammation by injection LPS into the mandible was associated with upregulation of both neuropeptides in the innervating neurons. Interestingly, denervation of the mandible with subsequent induction of inflammation abolished the stimulating effect of LPS and did not affect the neuropeptides production in the innervating neurons. This data adds further evidence that peripheral tissue injury is associated with alteration in neuropeptides expression in sensory neurons and that the nervous system contributes to the tissue inflammation through neuropeptides production and release peripherally [41-48]. Additionally, there is plasticity in neuronal neuropeptides expression which is injury dependent.

The denervation and the inflammation models used in this study showed the alteration in neuropeptides expression centrally. Previous studies using either model have shown similar changes peripherally in the local tissues [41-43]. Denervation models resulted in downregulation of neuropeptide locally in the periodontal bone [41,42] and LPS induced inflammation models resulted in upregulation of neuropeptides in the periodontal bone [42]. Peripheral nerve injury in the ankle joint reduced the expression of substance $\mathrm{P}$ and CGRP, while peripheral inflammation at the joint induced upregulation [44-48]. Similarly, in ferret trigeminal ganglia, the expression of substance $\mathrm{P}$ and CGRP was downregulated after sectioning the inferior alveolar nerve [17].

Neuropeptides are synthesized in the neurons and transported along the axons to the periphery [49]. Therefore, the local release of neuropeptides from peripheral nerve endings contributes to the inflammation directly by causing vasodilatation and increase vascular permeability resulting in neurogenic inflammation [2]. Moreover, neuropeptides contribute to the inflammation indirectly through the release of other inflammatory mediators such as nitric oxide, prostaglandins and collagenases from the peripheral terminals. Thus, neuropeptides are the major contributor to neurogenic inflammation with subsequent tissue destruction [49].

Sectioning the nerve results in a reduction in the local release of neuropeptides in the peripheral tissues [50-54]. This was attributed to the failure of transport [55] but we have shown here that this is also attributed to the lower neuropeptides production in the neurons. This 
Citation: Abd El-Aleem SA, Morales-Aza BM (2018) In Situ Hybridisation Study of Neuronal Neuropeptides Expression in Models of Mandibular Denervation with or without Inflammation: Injury Dependant Neuropeptide Plasticity. J Cytol Histol 9: 509. doi: 10.4172/2157-7099.1000509

Page 7 of 8

decrease in neuronal neuropeptides production could be attributed to the retrograde neuronal degeneration following tissue denervation [45] which results in the reduction of the number of neurons in the trigeminal ganglia $[50,56]$. Additionally, nerve sectioning results in loss of the noxious stimulus for neuropeptides synthesis in trigeminal ganglia [57].

Indeed, sensory neuron plasticity following peripheral tissue injury is considered important for understanding the development of chronic persistent pain $[46,47]$. This data was further confirmed in the combined denervation-inflammation model when mandibular denervation prior to LPS abolished the stimulating effect of LPS on neuronal neuropeptides production. Therefore, there is a neuronal circuit between the peripheral tissues and the innervating neurons, this account for the concomitant neuronal and local tissue responses to injury. In chronic disorder such as arthritis and periodontitis, the noxious stimulus is transmitted along the nerves causing excessive neuronal neuropeptide production [58]. The neuropeptides are transmitted along the nerves to the periphery and released locally from the nerve ending [59] causing further tissue destruction. Under this condition, denervation would interrupt this circus and minimize the pain and the tissue destruction [60].

In conclusion, neuropathic pain occurs because of tissue injury induced by inflammation or by nerve injury. This is associated with neuronal plasticity. The injury and the intense noxious stimuli stimulate nociceptive neurons. Furthermore, trigeminal nerve injury causes marked plasticity in neuropeptides production in the trigeminal ganglia suggesting that these neuropeptides may play a crucial role in the pathogenesis of orofacial neuropathic pain, in response to peripheral injury.

\section{Acknowledgement}

I am very grateful to Professor Bruce Mathews for the invaluable experience which aided the establishment of the models and to Professor Lucy Donaldson for the help with setting up the experiments, teaching the in-situ hybridization and supervising the work. This work was funded by a Medical Research Council Career Establishment Grant awarded to Professor Lucy Donaldson.

\section{References}

1. Goto T, Iwai H, Kuramoto E, Yamanaka A (2017) Neuropeptides and ATP signaling in the trigeminal ganglion. Japanese Dental Science. Review 53: 117-124.

2. Kristiansen KA, Edvinsson L (2010) Neurogenic inflammation: A study of rat trigeminal ganglion. The Journal of Headache and Pain 11: 485-495.

3. Lazarov NE (2002) Comparative analysis of the chemical neuroanatomy of the mammalian trigeminal ganglion and mesencephalic trigeminal nucleus. Prog Neurobiol 66: 19-59.

4. Skofitsch G, Jacobowitz DM (1985) Calcitonin gene-related peptide coexists with substance $\mathrm{P}$ in capsaicin-sensitive neurons and sensory ganglia of the rat. Peptides 6: 747-754.

5. Reuss S, Riemann R, Vollrath L (1992) Substance P and calcitonin generelated peptide-like immunoreactive neurons in the rat trigemina ganglion-with special reference to meningeal and pineal innervation. Acta Histochem 92: 104-109.

6. Lee Y, Kawai Y, Shiosaka S, Takami K, Kiyama H, et al. (1985) Coexistence of calcitonin gene-related peptide and substance P-like peptide in single cells of the trigeminal ganglion of the rat: an immunohistochemical analysis. Brain Res 330: 194-196.

7. Bae JY, Kim JH, Cho YS, Mah W, Bae YC (2015) Quantitative analysis of afferents expressing substance $\mathrm{P}$ : calcitonin gene-related peptide, isolectin
B4, neurofilament 200, and Peripherin in the sensory root of the rat trigeminal ganglion. J Comp Neurol 523: 126-138.

8. Luthman J, Johansson O, Ahlstrom U, Kvint S (1988) Immunohistochemical studies of the neurochemical markers: CGRP, enkephalin, galanin, gamma-MSH, NPY, PHI, proctolin, PTH, somatostatin, substance P, VIP, tyrosine hydroxylase and neurofilament in nerves and cells of the human attached gingiva. Arch Oral Biol 33: 149-158.

9. Gunjigake KK, Goto T, Nakao K, Konoo T, Kobayashi S, et al. (2006) Correlation between the appearance of neuropeptides in the rat trigeminal ganglion and reinnervation of the healing root socket after tooth extraction. Acta Histochem Cytochem 39: 69-77.

10. Mulderry PK, Ghatei MA, Spokes RA, Jones PM, Pierson AM, et al. (1988) Differential expression of alpha-CGRP and beta-CGRP by primary sensory neurons and enteric autonomic neurons of the rat. Neuroscience 25: 19.

11. Agur AMR, Dalley AE (2004) The cranial nerves. Grant's Atlas of Anatomy, Williams and Wilkins, Baltimore.

12. Lipari A, Lipari L, Carini F, Gerbino A, Farina E (2017) Somatotopy of the trigeminal complex: nerve, ganglion, nucleus. Editerranean Biomedical Journal 12: 170-177.

13. Shankland WE (2001) The trigeminal nerve: the mandibular division Cranio 19: 153-161.

14. Martin JH (2003) Neuroanatomy text and atlas. McGraw-Hill.

15. Fiehn NE, Klausen B, Evans RT (1992) Periodontal bone loss in Porphyromonas gingivalis-infected specific pathogen-free rats after preinoculation with endogenous Streptococcus sanguis. J Periodontal Res 27: 609-614.

16. Page RC (1991) The role of inflammatory mediators in the pathogenesis of periodontal disease. J Periodontal Res 26: 230-242.

17. Dumitrescu AL, Abd El Aleem S, Morales Aza B, Donaldson LF (2004) A model of periodontitis in the rat: Effect of lipopolysaccharide on bone resorption, osteoclast activity, and local peptidergic innervation. J Clin Periodontol 31: 596-603.

18. Linlin L, Yanzhi W, Jing Z, Ting Z, Shu L (2014) Healing of periodontal defects and calcitonin gene-related peptide expression following inferior alveolar nerve transection in rats. J Mol Hist 45: 311-320.

19. Bird EV, Long A, Boissonade FM, Fried K, Robinson PP (2002) Neuropeptide expression following constriction or section of the inferior alveolar nerve in the ferret. J Peripher Nerv Syst 7: 168-180.

20. Elcock C, Boissonade FM, Robinson PP (2001) Changes in neuropeptide expression in the trigeminal ganglion following inferior alveolar nerve section in the ferret. Neuroscience 102: 655-667.

21. Kvinnsland I, Kvinnsland S (1990) Changes in CGRP-immunoreactive nerve fibers during experimental tooth movement in rats. Eur J Orthod 12: 320-329.

22. Norevall Li, Forsgren S, Matsson L (1995) Expression of neuropeptides (CGRP, substance P) during and after orthodontic tooth movement in the rat. Eur J Orthod 17: 311-325.

23. Luthman J, Dahllof G, Modeer T, Johansson O (1988) Immunohistochemical study of neuronal markers in human gingiva with phenytoin-induced overgrowth. Scand J Dent Res 96: 339-346.

24. Barr-Agholme M, Modéer T, Luthman J (1998) Immunobiological study of neuronal markers in inflamed gingiva obtained from children with Down's syndrome. J Clin Periodontol 18: 624-633.

25. Donaldson LF, Harmar AJ, McQueen DS, Seckl JR (1992) Increased expression of preprotachykinin, calcitonin gene-related peptide, but not vasoactive intestinal peptide messenger RNA in dorsal root ganglia during the development of adjuvant monoarthritis in the rat. Brain Res Mol Brain Res 16: 143-149.

26. Donaldson LF, McQueen DS, Seckl JR (1995) Neuropeptide gene expression and capsaicin-sensitive primary afferents: maintenance and spread of adjuvant arthritis in the rat. J Physiol 486: 473-482.

27. Lawson SN, Crepps B, Perl ER (2002) Calcitonin gene-related peptide immunoreactivity and afferent receptive properties of DRG neurons in guinea-pigs. J Physiol 540: 989-1002. 
Citation: Abd El-Aleem SA, Morales-Aza BM (2018) In Situ Hybridisation Study of Neuronal Neuropeptides Expression in Models of Mandibular Denervation with or without Inflammation: Injury Dependant Neuropeptide Plasticity. J Cytol Histol 9: 509. doi: 10.4172/2157-7099.1000509

Page 8 of 8

28. Oku R, Satoh M, Fujii N, Otaka A, Yajima H, et al. (1987) Calcitonin gene-related peptide promotes mechanical nociception by potentiating the release of substance $\mathrm{P}$ from the spinal dorsal horn in rats. Brain Res 403: 350-354.

29. Biella G, Panara C, Pecile A, Sotgiu ML (1991) Faciliatory role of calcitonin gene-related peptide (CGRP) on excitation induced by substance $\mathrm{P}$ (SP) and noxious stimuli in rat spinal dorsal horn neurons. An iontophoretic study in vivo. Brain Res 559: 352-356.

30. Gaspersic R, Kovacic U, Cör A, Skaleric U (2008) Unilateral ligatureinduced periodontitis influences the expression of neuropeptides in the ipsilateral and contralateral trigeminal ganglion in rats. Archives of Oral Biology 53: 659-665.

31. De Avila ED, de Molon RS, de Godoi Gonçalves DA, Camparis CM (2014) Relationship between levels of neuropeptide Substance P in periodontal disease and chronic pain: a literature review. J Investig Clin Dent 5: 91-97.

32. Messlinger K, Fischer MJ, Lennerz JK (2011) Neuropeptide Effects in the Trigeminal System: Pathophysiology and Clinical Relevance in Migraine. Keio J Med 60: 82-89.

33. Cady RJ, Glenn JR, Smith KM, Durham PL (2011) Calcitonin generelated peptide promotes cellular changes in trigeminal neurons and glia implicated in peripheral and central sensitization. Mol Pain 7: 94.

34. Goadsby PJ, Holland PR, Martins-Oliveira M, Hoffmann J, Schankin C et al. (2017) Pathophysiology of migraine: A disorder of sensory processing. Physiological Reviews 7: 553-622.

35. Ashina M, Bendtsen L, Jensen R, Schifter S, Jansen-Olesen I, et al. (2000) Plasma levels of calcitonin gene-related peptide in chronic tension-type headache. Neurology 55: 1335-1340.

36. Reilly CA (2010) Neurogenic Inflammation: TRP Ion Channels in the Lung. In: McQueen CA, (2ndedn), Comprehensive toxicology. Elsevier, Oxford, pp: 129-149.

37. Basbaum AI (1991) The contribution of the nervous system to inflammation and inflammatory disease. In: Stanley TH, Ashburn MA, Fine PG (eds.) Anesthesiology and pain management, Developments in critical care medicine and anesthesiology. Springer, Dordrecht.

38. Preshow PM (2000) Host response modulation in periodontics. Periodontol 2008: 92-110.

39. Seymour GJ, Ford PJ, Cullinan MP, Leishman S, Yamazaki K (2007) Relationship between periodontal infections and systemic disease. Clin Microbial Infect 13: 3-10.

40. Yu XJ, Zhang L, Liu S, Du Yan-Mei, Wang W, et al. (2016) Expression of substance $\mathrm{P}$ in rat periodontal alveolar bone after denervation. Int J Clin Exp Pathol 9: 1384-1391.

41. Yu X, Lv L, Zhang J, Zhang T, Xiao C, et al. (2015) Expression of neuropeptides and bone remodelling related factors during periodontal tissue regeneration in denervated rats. J Mol Histol 46: 195-203.

42. Linlin L, Yanzhi W, Ting Z, Shu L (2014) Healing of periodontal defects and calcitonin gene-related peptide expression following inferior alveolar nerve transection in rats. J Mol Hist 45: 311-320.

43. Lundy F, Linden G (2004) Inflammation. Critical 15: 82-98.
44. Hirose K, Iwakura N, Orita S (2010) Evaluation of behaviour and neuropeptide markers of pain in a simple, sciatic nerve-pinch pain model in rats. Eur Spine J 19: 1746-1752.

45. Zhang X, Xu ZO, Shi TJ (1998) Regulation of expression of galanin and galanin receptors in dorsal root ganglia and spinal cord after axotomy and inflammation. Ann NY Acad Sci 863: 402-413.

46. Hanesch U, Pfrommer U, Grubb BD, Heppelmann B, Schaible HG (1993) The proportion of CGRP-immunoreactive and SP-mRNA containing dorsal root ganglion cells is increased by a unilateral inflammation of the ankle joint of the rat. Regul Pept 46: 202-203.

47. Weihe E, Nohr D, Schafer MK (1995) Calcitonin gene-related peptide gene expression in collagen-induced arthritis. Can J Physiol Pharmacol 73: 1015-1019.

48. Calza L, Pozza M, Zanni M, Manzini CU, Manzini E, et al. (1998) Peptide plasticity in primary sensory neurons and spinal cord during adjuvantinduced arthritis in the rat: an immunocytochemical and in situ hybridization study. Neuroscience 82: 575-589.

49. Chiu IM, Hehn CA, Woolf CJ (2012) Neurogenic inflammation. The peripheral nervous system's role in host defence and immunopathology. Nature neuroscience 15: 1063-1067.

50. Aldskogius H, Arvidsson J (1978) Nerve cell degeneration, and death in the trigeminal ganglion of the adult rat following peripheral nerve transection. J Neurocytol 7: 229-250.

51. Navarro X, Vivo M, Valero-Cabre A (2007) Neural plasticity after peripheral nerve injury and regeneration. Prog Neurobiol 82:163-201.

52. Randi L, Chuang L, Gong-Wei L, Annika R, Kamal M, et al. (2017) Neuronal plasticity of trigeminal ganglia in mice following nerve injury. Journal of Pain Research 10: 349-357.

53. Grassel S, Muschter D (2017) Peripheral nerve fibers and their neurotransmitters in osteoarthritis pathology. International Journal of Molecular Sciences 18: 931.

54. Fu C, Yin Z, Yu D, Yang Z (2013) Substance P and calcitonin gene-related peptide expression in dorsal root ganglia in sciatic nerve injury rats. Neural Regeneration Research 8: 3124-3130.

55. Ji R, Woolf C (2001) Neuronal plasticity and signal transduction in nociceptive neurons: Implications for the initiation and maintenance of pathological pain. Neurobiology of Disease 8: 1-10.

56. Bondok AA, Sansone FM (1984) Retrograde and transganglionic degeneration of sensory neurons after a peripheral nerve lesion at birth. Experimental Neurology 86: 322-330.

57. Woolf CJ, Qiufu M (2007) Nociceptors noxious stimulus detectors. Neuron 55: 353-364.

58. Campbell JN, Meyer RA (2006) Mechanisms of neuropathic pain. Neuron 52: 77-92.

59. Dubin AE, Patapoutian A (2010) Nociceptors: the sensors of the pain pathway. The Journal of Clinical Investigation 120: 3760-3772.

60. Choi EJ, Choi YM, Jang EJ, Kim JY, Kim TK, et al. (2016) Neural ablation and regeneration in pain practice. The Korean Journal of Pain 29: 3-11. 